\title{
К ПРОБЛЕМЕ СЛОВОИЗМЕНИТЕЛЬНОЙ СИСТЕМЫ РУССКОГО И ПОЛЬСКОГО ГЛАГОЛА
}

\section{The Problematic of Conjugation with Russian and Polish Verbs}

Keywords: verb, conjugation, terminology, Russian language, Polish language

Contact: Ostravská univerzita; mon.stenchlakova@gmail.com

\section{К актуальности проблемы}

Проблема глагольного словоизменения в настоящем времени актуальна. На основе сходств и расхождений в языках, происходящих из одной языковой семьи можно лучше понять структуру и функционирование славянских языков, их историческое развитие и его последующее влияние на актуальное состояние языка вообще. Сравнение славянских языков также помогает в осознании актуальных тенденций, происходящих в данных языках, и в улучшении коммуникации среди носителей славянских языков. Основная цель статьи сравнение системы словоизменения глагола в русском и польском языках, указать сходства и расхождения в функционировании глагола как полнознаменательной части речи.

\section{Характеристика глагола и его морфологические категории}

Сопоставляя глагольные системы русского и польского языков, в начале статьи следует определить и классифицировать глагол с разных точек зрения. Ниже представлены основные определения глагола, ссылающиеся на источники русского и польского языков.

Словарь лингвистических терминов Т. В. Жеребило ссылается на факт, что глагол, во-первых, это самостоятельная часть речи, которая обозначает процессуальный признак предмета (действие, отношение или состояние) в грамматических категориях глагола, причем в разных языках набор морфологических признаков глагола разнообразный. Во-вторых, глагол считается одним из языковых средств, которое употребляется в разных стилях 
в художественной литературе (Жеребило 2010: 73). Ссылаясь на определение глагола в польском языке, П. Бонк описывает глагол не только как часть речи, выражающую действие или процесс, но также как определение изменений, которые происходят в природе (woda marznie, liście schna, wiater wieje) (Bąk 2004: 177).

Глагол является одной из основных частей речи, что подтверждает также Э. Сепир. Автор на счет глагола отмечает: «какой бы неуловимый характер ни носило в отдельных случаях различение имени и глагола, нет такого языка, который бы пренебрегал этим различением. Иначе обстоит дело с другими частями речи. Ни одна из них для жизни языка не является абсолютно необходимой» (Сепир 1993: 116). На основе его утверждений можно отметить, что глагол вместе с существительным считаются главными и основными частями речи, а также самыми важными элементами почти каждого языка. Предметы и лица выражены существительными, а действия, которые они совершают, обозначаются глаголами.

Само происхождение термина «глагол» можно найти в латинском языке verbum, либо в греческом языке - rema. Такого рода наименования возможно перевести с помощью термина «слово». Параллели термина можно исследовать также в древнерусском языке, в котором слово «глаголити» обозначало «говорить» (Сидоренко 2017: 194).

Для того, чтобы характеризовать грамматическое значение глагола с помощью морфологических категорий, необходимо рассмотреть глагол с семантической точки зрения. Семантика имеет важное значение для морфологической характеристики глаголов. Семантическое значение играет важную роль прежде всего в категории вида. Для правильного определения глагольного вида необходимо работать с различиями в семантике данного глагола. Семантика также играет роль в определении категории времени, наклонения и лица. Доказательство такого рода утверждений: невозможно определить лицо или образовать форму повелительного наклонения от глаголов, описывающих некоторые явления природы (Grzegorczykowa, Laskowski, Wróbel 1999: 152).

Морфологические категории описывают и показывают грамматическое значение слова. Каждый глагол имеет свой состав форм. Все формы глагола охватываются категорией залога и вида. Остальные морфологические категории можно исследовать и анализировать только в конкретных формах, как, например, спрягаемые формы глагола, инфинитив, деепричастие и др. (Шведова 1980: 580). 
Грамматическими категориями времени, числа, наклонения, лица, рода обладают упомянутые выше спрягаемые формы глагола. В отличие от инфинитива и деепричастия, у которых встречается только категория вида и залога, причастие обладает категорией времени (в формах настоящего и прошедшего времени), рода, числа и падежа. Глаголы славянских языков имеют развитую систему форм. В русском языке полная парадигма глагола включает в себя более 200 форм. В парадигму конкретного глагола входят все формы лица, рода, времени, наклонения, числа, залога и вида (Кузнецова 2009: 100).

\section{Спряжение глагола в русском языке}

Спряжение - это изменение спрягаемых форм глагола по лицам, числам, временам, наклонениям, в некоторых типах глаголов и по родам. В русском языке выделяются два типа спряжения - первое (I) спряжение и второе (II) спряжение (Шведова 1980: 644).

Словарь лингвистических терлинов Т. В. Жеребило ссылается на факт, что в современном русском языке выделяются не только первое и второе спряжения глаголов, а также необходимо обратить внимание на разноспрягаемые и изолированные глаголы (Жеребило 2010: 363).

В процессе образования личных форм глаголов при спряжении нужно учитывать три основных признака, т. е. систему флексий, окончательную согласную основы и чередование согласных в конце основы (Шведова 1980: 645).

В русском языке можно определить тип спряжения либо по личному окончанию, либо по инфинитиву. Если в 3-ем лице мн. числа встречается окончание -ym / -ют, то глаголы относятся к I спряжению, если в 3-ем лице мн. числа наблюдается окончание - $a m$ / -яm, то глаголы относятся ко II спряжению.

Следует отметить, что есть также ситуации, в которых окончание глагола безударное и трудно определить к какому типу спряжения данный глагол относится. В таком случае определить тип спряжения глагола можно по инфинитиву. Можно констатировать, что ко II спряжению относятся глаголы на -ить, за исключением глаголов брить, стелить, зиждиться, зыбиться, некоторых глаголов на -ать (знать, держать, дылиать и сльшать), а также 7 глаголов на -еть (смотреть, вертеть, видеть, ненавидеть, зависеть, обидеть, mерпеть). К I спряжению относятся остальные глаголы, у которых безударное спорное окончание (Сидоренко 2017: 206-207). 
При спряжении глаголов как I спряжения, так и II спряжения в настоящем времени нужно обратить внимание на чередование согласных в основе глагола. В русском языке встречаются чередования конечного согласного в основе настоящего времени.

Если наблюдается чередование у глаголов I спряжения, изменяется согласный в основе глагола во всех лицах. Исключение составляют глаголы типа печь (беречь, мочь, ...), у которых особый тип чередования согласного. У такого типа глаголов происходит чередование конечного согласного в 1-м лице единственного числа и в 3-ем лице мн. числа (печb - я пеку, mы печешь, он печет, мы печем, вы печете, они пекут) (С̌́ára 1986: 72). В процессе чередования у глаголов II спряжения изменяется конечный согласный в основе глагола в 1-м лице ед. числа. Во всех остальных лицах ед. и мн. числа остается согласный в тот же самой форме, как и в форме инфинитива (ходить - я хожс, ты ходишь, он ходит, мы ходим, вы ходите, они ходят) (С̌́ára 1986: 72).

Особую группу составляют т. наз. разноспрягаемые глаголы. Образцовым примером такого рода глаголов являются глаголы хотеть и бежать. Они входят в данную группу, так как они спрягаются частично по I спряжению и отчасти по II спряжению. Глагол хотеть спрягается в ед. числе по I спряжению (я хочу, ты хочешь, он хочет), а в мн. числе по II спряжению (мы хотим, вы хотите, они хотят). Глагол бежать является разноспрягаемым, так как во всех лицах как ед. числа, так мн. числа, за исключением 3-го лица мн. числа, спрягается по II спряжению (я бегу, ты бежишь, он бежит, мы бежим, вы бежите). 3-е лицо мн. числа соответствует I спряжению (они бегут).

Глаголы есть (я ем, ты ешь, он ест, мы едим, вы едите, они едят) и дать (я дам, ты дашь, он даст, мы дадим, вы дадите, они дадут), а также производные от них глаголы типа надоесть или создать считаются особоспрягаемыми. Они относятся к архаическому типу спряжения (Сидоренко 2017: 207).

В группу разноспрягаемых глаголов входят также глаголы типа быms, eхать, идти. Они спрягаются по правилам I спряжения. Их особенностями считаются основы настоящего времени - буд-, ед- и ид-, к которым присоединяются окончания I спряжения (я ед-y, mbl ед-ешь, он ед-ет, мы ед-ем, вы ед-ете, они ед-уm) (Rudincová 2004: 31).

В русском языке выделяется также группа т. наз. недостаточных глаголов. В данную группу входит ряд глаголов, у которых отсутствует способность образовывать формы 1-го лица ед. числа (бдеть, убедить, победить и др.). С теоретической точки зрения их образовать можно, но в практическом плане 
современного русского языка они не используются. Для выражения формы 1-го лица используется аналитическая форма со вспомогательными глаголами (хочу убедить, смогу сопеть, могу победить) (Сидоренко 2017: 208).

\section{Спряжение глагола в польском языке}

В польском языке можно дать определение термину «спряжение» такое же, как и в русском языке. Спряжение - это изменение глагола по лицам, числам, временам, родам, наклонениям в форме прошедшего или будущего времени, и в форме сослагательного наклонения.

В состав спряжения в польском языке входят личные формы глаголов, а также действительные и страдательные причастия (Bąk 1977: 286-287). В современном польском языке выделяются четыре основных типа спряжения. Их можно выделить на основе окончаний в 1-ом и во 2-ом лице единственного числа настоящего времени.

Глаголы I спряжения (в польском языке т. наз. konjugacja I) характеризуются окончаниями -е в 1-ом лице и -esz во 2-ом лице ед. числа настоящего времени (ja pisz-e, ty pisz-esz, on pisze, my piszemy, wy piszecie, oni pisza) (Bąk 1977: 289).

Глаголы II спряжения (в польском языке т. наз. konjugacja II) характеризуются окончаниями -е в 1-ом лице и -isz / -ysz во 2-ом лице ед. числа наст. времени. Если основа заканчивается на cz, szcz, sz, ż/rz, żdż, то в окончании получается -y (ja mówię, ty mówisz, on mówi, my mówimy, wy mówicie, oni mówia; ja stysze, ty styszysz, on słyszy, my styszymy, wy styszycie, oni słysza) (Bąk 1977: 289).

Глаголы III спряжения (в польском языке т. наз. konjugacja III) характеризуются окончаниями -am в 1-ом лице и -asz во 2-ом лице ед. числа наст. времени (ja kocham, ty kochasz, on kocha, my kochamy, wy kochacie, oni kochaja). Основа всех глаголов данного спряжения в 3-ем лице мн. числа расширяется за счет согласного -j- (Bąk 1977: 289, 293). В III спряжении не происходит никакого чередования. Глагол dać можно считать исключением, так как в 3-ем лице мн. числа наблюдается чередование (ja dam, ty dasz, on da, my damy, wy dacie, oni dadza) (Bartnicka, Satkiewicz 1995: 95).

Глаголы IV спряжения (в польском языке т. наз. konjugacja IV) характеризуются окончаниями -em в 1-ом лице и -esz во 2-ом лице ед. числа наст. времени. В группу IV спряжения входит лишь определенная группа глаголов jem, śmiem, wiem, umiem, rozumiem и производные от них глаголы. Основа 
глаголов IV спряжения в 3-ем лице мн. числа расширяется за счет согласных -j- / -dz-(ja wiem, ty wiesz, on wie, my wiemy, wy wiecie, oni wiedza) (Bąk 1977: 289).

При спряжении глаголов в польском языке необходимо обратить внимание на чередование не только согласных, но и гласных.

Во-первых, придется объяснить чередование гласных. При I спряжении у нескольких глаголов типа niesśc, pleść, wieźć и других наблюдается чередование гласных о//е. Глаголы такого типа встречаются в польском языке довольно часто. Чередование гласных происходит в форме 1-го лица ед. числа и в форме 3-го лица мн. числа (pleść - ja plote, ty pleciesz, on plecie, my pleciemy, wy pleciecie, oni plota). Наряду с чередованием гласных может встречаться одновременно чередование согласных (Bąk 1977: 290).

Во-вторых, следует определить богатую систему чередования согласных в польских глаголах I спряжения. Чередование твердых согласных с мягкими согласными происходит во многих глаголах I спряжения. Твердый согласный остается в 1-ом лице ед. числа и в 3-ем лице мн. числа наст. времени. Во всех остальных формах твердый согласный чередуется с мягким по правилам польского языка. В польском языке наблюдается чередование следующих согласных: m//m, w//ẃ (ja rwę, ty rwiesz, on rwie, my rwiemy, wy rwiecie, oni rwa), t//ć, d//dź (ja jadę, ty jedziesz, on jedzie, my jedziemy, wy jedziecie, oni jada), s//ś, z//ź, $\mathrm{n} / / \mathrm{n}, \mathrm{r} / / \mathrm{rz}$ (ja biorę, ty bierzesz, on bierze, my bierzemy, wy bierzecie, oni biorq) (Bartnicka, Satkiewicz 1995: 94).

В польском языке встречается также чередование k//cz (ja pieke, ty pieczesz,

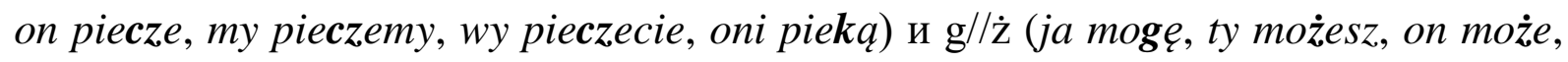
my możemy, wy możecie, oni moga). Данный тип спряжения основан на историческом правиле (Bąk 1977: 291).

Во II спряжении чередование согласных не происходит, если основа глагола оканчивается на мягкий согласный. Такое явление имеет объяснение в историческом развитии языка. Чередование гласных во II спряжении не встречается.

Существует группа согласных, которые чередуются с фонетически мягкими согласными с//ć (ja kręcę, ty kręcisz, on kręci, my kręcimy, wy kręcicie, oni kręca), dz//dź (ja chodzę, ty chodzisz, on chodzi, my chodzimy, wy chodzicie, oni chodza), sz//ś (ja gaszę, ty gasisz, on gasi, my gasimy, wy gasicie, oni gasza), ż//ź, dż//dź (Bartnicka, Satkiewicz 1995: 94-95). 


\section{Сопоставление словоизменительной системы русского и польского глаголов}

Глагол является полнознаменательной, самостоятельной частью речи в обоих славянских языках. Глагол наряду с существительным можно считать самыми главными частями речи в грамматическом строе многих языков, в том числе и славянских. Они обозначают предметы, животных, людей и дают основную характеристику того, что делают. У других частей речи нет такой важной коммуникативной и номинативной функции. В славянских языках можно встретить множество сходств потому, что они произошли из одного языка общеславянского (праславянского) языка. Однако, постепенно формировались отдельные языки на протяжении лет. Поэтому не только в словарном составе языка, а также в грамматической системе данных языков появилось много отличий. Ниже рассмотрены как сходства, так различия, касающиеся проблематики словоизменительной системы русского и польского глаголов.

Как русские, так польские лингвисты относятся к характеристике глагола как части речи подобным образом. В русских и польских грамматиках можно встретить различные дефиниции, но все согласуются с тем, что глагол - это самостоятельная часть речи, которая обозначает действие, отношение или состояние. Необходимо отметить, что в каждом языке используется набор разных морфологических признаков глагола.

Морфологические категории у глагола в польском и русском языках те же самые - категория времени, числа, наклонения, лица, рода, которыми обладают спрягаемые формы глагола, категория вида и залога у инфинитива и деепричастия, а также категория времени у причастий. Каждый из языков использует особенную терминологическую номинацию отдельных категорий, а также свои средства для их выражения.

Категория времени тоже работает на схожих принципах, но при образовании несовершенного будущего времени можно наблюдать различия. В польском языке данный тип будущего времени образуется при помощи глагола быmь + формы прошедшего времени, а в русском языке с помощью глагола быть + инфинитив.

Проблематика безличных глаголов свойственна скорее русскому языку, в котором безличные глаголы делятся на две группы: глаголы с постфиксом -ся и глаголы без постфикса -ся. В польском языке также существует понятие безличный глагол, однако это понятие относится к неспрягаемой форме глагола прошедшего времени (wynajęto, przyznano, śpiewano). 
При проблематике сослагательного наклонения можно также найти различия. В русском языке сослагательное наклонение образуется посредством

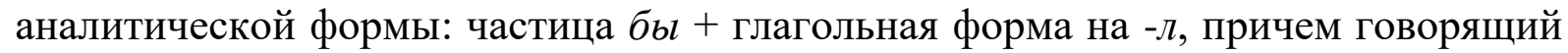
не несет ответственность за реализацию сказанного. Однако в польском языке выделяется форма, обозначающая действие, которое либо считается нереальным, либо не произошло, или форма, обозначающая возможность реализации действия, ситуации.

Остальные морфологические категории в обоих языках работают на схожих принципах, различаются только по формам, характерным для системы данного языка.

К системе спряжения русский и польский языки подходят разнообразно. У каждого есть своя система. В русском языке выделяются два основных типа спряжения - I и II спряжение. В польском языке выделяются четыре типа спряжения.

В русском языке при I спряжении присутствует гласный -e- / -ё- в формах 2-го и 3-го лица в ед. числе и в форме 1-го, 2-го лица в мн. числе. Кроме гласного -e- / -ё- важно присутсвие гласного -y- / -ю-, выступающего в форме 3-го лица в мн. числе. При II спряжении надо обратить внимание на присутствие гласного -uв формах 2-го и 3-го лица в ед. числе и в форме 1-го, 2-го лица в мн. числа. Кроме гласного -u- также важно присутствие гласного - $a$ - / -я-, выступающего в форме 3-го лица в мн. числе.

В польском языке тип спряжения выделяется на основе окончаний в 1-ом и во 2-ом лице ед. числа настоящего времени. I спряжение характеризуется окончаниями -е в 1-ом лице и -esz во 2-ом лице. II спряжение характеризуется окончаниями -е в 1-ом лице и -isz / -ysz во 2-ом лице. III спряжение характеризуется окончаниями -am в 1-ом лице и -asz во 2-ом лице. IV спряжение характеризуется окончаниями -em в 1-ом лице и -esz во 2-ом лице, но в группу данного спряжения входит лишь несколько глаголов - jem, śmiem, wiem, umiem, rozumiem и производные от них глаголы.

Как в русском, так в польском языках происходит чередование согласных. $\mathrm{У}$ каждого из языков своя система и условия чередования согласных, в польском языке также сильно развита система чередования гласных. В польском языке чередование характерно только для I и II сряжений. Русский язык наряду с другими славянскими языками выделяет группу разноспрягаемых глаголов. В польском языке такую группу на основе нормативных грамматик традиционно 
не выделяют. Все глаголы входят в систему данных спряжений, существуют только исключения или глаголы, у которых наблюдается чередование.

\section{Summary}

The main theme of this thesis was working with theory and comparing of the problematic with verb conjugation in selected Slavic languages - Russian and Polish language. The aim of the first part was to define the term verb itself from different aspects such as Russian, Polish and also some linguists all around the world. The following parts explained how the rules for conjugation worked in both languages. There was the description of Russian system of conjugation and of Polish system of verb conjugation. The last part was described as a comparing form of the verb itself and its conjugation. The main theme of this work was creating the systematic comparison of the problematic with verb conjugation in selected Slavic languages and displayed the correspondence and differences in languages that are related to one language family.

\section{Литература}

Ермолович, Д. И. Правила практической транскрипиии имен и названий с 29 западных и восточных языков на русский и с русского языка на английский. Москва: Аудитория, 2016.

Жеребило, Т. В. Словарь лингвистических терминов. Назрань: ООО «Пилигрим», 2010.

Кузнецова, Т. В. Современный русский язык. Морфология. Учебное пособие для студентов факультета русской словесности. Саратов: ИЦ «Наука», 2009.

Сепир, Э. Избранные труды по языкознанию и культурологии. Москва: «Прогресс», «Универс», 1993.

Сидоренко, Е. Н. Морфология современного русского языка. Части речи и контаминанты. Москва: ФЛИНТА «Наука», 2017.

Шведова, Н. Ю. и др. Русская грамматика. Москва: Наука, 1980.

Bartnicka, B., Satkiewicz, H. Gramatyka języka polskiego dla cudzoziemców. Warszawa: WP, 1995.

Bąk, P. Gramatyka języka polskiego: zarys popularny. Warszawa: WP, 1977.

Bąk, P. Gramatyka języka polskiego: zarys popularny. Warszawa: WP, 2004.

Čára, V. Ruská mluvnice pro střední školy. Praha: SPN, 1968. 
Grzegorczykowa, R., Laskowski, R., Wróbel, H. Gramatyka współczesnego języka polskiego. Morfologia. Warszawa: Wydawnictwo Naukowe PWN, 1999.

Rudincová, B. Funkční gramatika ruského jazyka I. Ostrava: Ostravská univerzita, 2004. (c) $\$$ BY NC ND $\begin{aligned} & \text { The article is accessible in open access mode under licence CC BY-NC-ND } \\ & \text { Creative Commons Attribution-NonCommercial-NoDerivatives } 4.0\end{aligned}$ 